\title{
Cellulose Nanofibers Preparation from Cassava Peels via Mechanical Disruption
}

\author{
Sonny Widiarto ${ }^{1,2, *}$, Edi Pramono ${ }^{1,3} \oplus$, Suharso ${ }^{2}$, Achmad Rochliadi ${ }^{1}$ and I Made Arcana ${ }^{1, *}$ \\ 1 Inorganic and Physical Chemistry Research Division, Institut Teknologi Bandung, Jl. Ganesha 10, \\ Bandung 40132, Indonesia; edi.pramono.uns@gmail.com (E.P.); achmad@itb.ac.id (A.R.) \\ 2 Department of Chemistry, Faculty of Mathematics and Natural Sciences, Lampung University, Jl. Prof.Dr. S. \\ Brodjonegoro 1, Bandar Lampung 35145, Indonesia; suharso@fmipa.unila.ac.id \\ 3 Department of Chemistry, FMIPA, Universitas Sebelas Maret, Jl. Ir. Sutami 36A, Surakarta 57126, Indonesia \\ * Correspondence: sonnywidiarto@gmail.com (S.W.); arcana@chem.itb.ac.id (I.M.A.); \\ Tel.: +62-85267974746 (S.W.)
}

Received: 8 December 2018; Accepted: 13 May 2019; Published: 15 May 2019

\begin{abstract}
In this study, cellulose and cellulose nanofibers (CNF) were extracted and prepared from cassava peels (CPs). The method of the cellulose extraction was performed by alkali treatment followed by a bleaching process. The CNF were prepared by mechanical disruption procedure (homogenization and ultrasonication), and the results were compared with a common acid hydrolysis procedure. The resulting cellulose and CNF from both procedures were then analyzed using FTIR, SEM, TEM, XRD, and TGA. The results show that cellulose and CNF were successfully prepared from both procedures. The physical properties of the produced CNF were different; however, they had similar chemical properties.
\end{abstract}

Keywords: agriculture waste; cassava peels; cellulose; cellulose nanofibers

\section{Introduction}

The utilization of agriculture industrial waste became an interesting issue in recent years due to environmental and economic consideration. Cassava (Manihot esculenta Cranz) is one of the major tropical crops and a high source of carbohydrates grown in tropical and subtropical regions [1]. Indonesia has become the third largest producing country of cassava, with production approaching 25 million tons at the end of 2015 [2]. Cassava industrial processing is performed mainly to separate starch from the roots, which generates highly abundant solid wastes, including bagasse and peels. The resulting cassava bagasse is a starchy, fibrous, and very moist material [3]. This is used for bioethanol, compost production, cattle feed, and filler in pasta and sauces. Without any processing, cassava peels (CPs) are usually discarded in the surroundings, such as a landfill [4]. The peeling fraction and bagasse obtained has been found to be around 11 and $12 \%$, respectively, of the dried cassava root mass [5]. The chemical content of CP is $37.9 \%$ cellulose [6-8], 23.9\% hemicellulose, and 7.5\% lignin [6]. Other researchers found the cellulose contained in CP to be lower, reported $14.8 \%$ by Leite et al. [5]. Thus, $\mathrm{CP}$ is a rather promising source of cellulose as an alternative to wood consumption.

Cellulose is a natural polymer material, which is renewable, prolific, and decomposable. It has a big molecular weight (exceeding $500.000 \mathrm{Da}$ ) and long chain polymer with the range of size from 10 to 350 in the dimension of nanometers $[9,10]$. Nanocellulose can be called nanoparticles that have distinguished physical characteristics that could be used to improve the mechanical properties of polymer nanocomposites [11,12].

Amid the numerous techniques to produce nanocellulose, the acid hydrolysis method-as the most famous method-is generally applied [12]. This method is appropriate and produces nanocellulose 
quickly and with better properties. It disrupts the irregular, shapeless, and amorphous portion of cellulose that can eliminate single and perfect crystal. There are numerous phases in the method, i.e., hydrolysis of cellulose with strong acid under arranged conditions; controlling of hydrolysis procedure with adding water; centrifugation; using a cellulosic membrane to do dialysis, followed by ultrasonication and, finally, drying of the last suspension product $[13,14]$. The drawback from this procedure is that it is time-consuming and its big volume consumption of acid. The preparation of nanocellulose from $1 \mathrm{~g}$ of dried cellulose requires approximately $10 \mathrm{~mL}$ of saturated sulphuric acid.

The study of nanocellulose from cassava bagasse has been investigated by some researchers [3,12-15]. However, so far, only Leite et al. [5] had examined cellulose nanofibers (CNF) from CPs. All mentioned researchers obtained the CNF using hydrolysis method by sulphuric acid in the range concentration of 36-64 wt.\%.

Thus, the aim of this study was to examine the procedure of CNF preparation from CPs by eluding the acid hydrolysis step. In this study, the mechanical disintegration procedure was applied to generate the CNF. So far, there are no published articles on the using of mechanical disruption procedure for the preparation of $\mathrm{CNF}$ from $\mathrm{CPs}$. This procedure will minimize the use of chemical reagent and reduce the cost production of CNF.

\section{Materials and Methods}

\subsection{Materials}

The CPs were collected from a local industrial cassava chip in Bandar Lampung, Indonesia. All other chemicals, such as sulphuric acid, sodium hypochlorite, pure microcrystalline cellulose (MCC), and sodium hydroxide, were purchased from Sigma-Aldrich (Singapore).

\subsection{Isolation of Cellulose}

Before isolating cellulose, inner $\mathrm{CP}$ was obtained by separating from the outer shell. Then it was cleaned and ground into a suspension. The obtained suspension was air-dried under the sun for $48 \mathrm{~h}$. Ten grams of dried CP were mixed into $0.2 \mathrm{~L}$ of $\mathrm{NaOH} 4 \%$ to be refluxed for $120 \mathrm{~min}$ at constant agitating rate and temperature of $90{ }^{\circ} \mathrm{C}$. The blend was bleached using $0.1 \mathrm{~L}$ of $\mathrm{NaOCl}$ $4 \%(\mathrm{w} / \mathrm{v})$ for $60 \mathrm{~min}$ at the constant agitation and temperature of $80^{\circ} \mathrm{C}$. The resulting residue was cleaned by deionized water up to a neutral $\mathrm{pH}$ and continued with drying the residue for $24-36 \mathrm{~h}$ at room temperature.

\subsection{Preparation of $\mathrm{CNF}$}

CNF were prepared from the isolated cellulose by two different procedures. Procedure I: Isolated cellulose colloidal suspension from CP was stirred in an AE300L-H 70G Homogenizer (Yason, Zhejiang, China) for $10 \mathrm{~min}$ at 10,000 rpm. This step was followed by ultrasonication, Sonics Vibracell (Newton, CT, USA) $0.5 \mathrm{~J}$ for $0.5 \mathrm{~h}$. Next, stirred cellulose was refined through a 100-mesh sieve to gain a homogenous particle size. This procedure was then compared to CNF produced by acid hydrolysis. Procedure II: The preparation of nanofibers with the acid hydrolysis procedure has been mentioned in previous work [16] and described as follows. The addition of $\mathrm{H}_{2} \mathrm{SO}_{4}$ solution $64 \%(\mathrm{w} / \mathrm{w})$ with a ratio of 25:1 between $\mathrm{H}_{2} \mathrm{SO}_{4}$ and cellulose was carried out to isolate cellulose using hydrolysis process at temperature of $50^{\circ} \mathrm{C}$ for $120 \mathrm{~min}$. In order to quench the process of hydrolysis, the an extra $250 \mathrm{~mL}$ deionised water was added into the reaction blend. The product was obtained as suspension of colloid and then centrifugation of 14,000 rpm was applied to the product for $10 \mathrm{~min}$ under the condition of temperature $-4{ }^{\circ} \mathrm{C}$ followed with the dialyzing process for 5 days to obtain neutral product and free of sulphate ions. The product was homogenized to produce nanocellulose using the ultrasonication process for $0.5 \mathrm{~h}$. 


\subsection{Cellulose and CNFCharacterization}

The purity of cellulose and the portion of hemicellulose in the resulting cellulose wasdetermined by TAPPI $203 \mathrm{~cm}-99$ technique [17], whether the lignin content was decided as Klason lignin [18]. Characterizations of raw $\mathrm{CP}, \mathrm{CP}$ cellulose, and $\mathrm{CP} C \mathrm{CNF}$ in terms of surface morphology were investigated with SEM Zeiss MA 10 (Oberkochen, Germany). The samples were gold-sputtered to avoid charging. Investigation of existed functional groups in the material was performed by FTIR Shimadzu Prestige 21 (Shimadzu, Kyoto, Japan) in the measurement range of 4000 to $500 \mathrm{~cm}^{-1}$. TEM, JEOL JEM 1400 (Tokyo, Japan) was applied to investigate the morphology of colloid material. A small amount of a dilute suspension of nanofibers was put on a $\mathrm{Cu}$ grid coated with a thin carbon film. Then, at room temperature, this specimen was dried and, finally, stained with Ruthenium vapor. The diameter of nanofibers was measured with ImageJ 1.52G software (Wayne Rasband NIH, Washington DC, USA). Characterization of material by the XRD was performed using Bruker D8 Advance (Billerica, Massachusetts, USA). The index of crystallinity (CI) was calculated by Segal equation:

$$
C I(\%)=\frac{\left(I_{200}-I_{a m}\right)}{I_{200}} \times 100
$$

where $I_{200}$ and $I_{a m}$ are the crystalline region and the amorphous region peak intensity, respectively.

\section{Results and Discussion}

\subsection{Chemical Composition of $C P$ and Its Nanocellulose}

$\mathrm{CP}$ is potentially recognized as a raw material of biomass, like cellulose, produced in an environmentally-friendly, low-cost, innovative product. The chemical composition of dried $\mathrm{CP}, \mathrm{CNF}$ the resulted from procedures I and II was investigated and the obtained data are shown in Table 1. In this study, the dried raw $\mathrm{CP}$ contained as much as $40.5 \%$ cellulose. This achievement is almost same as the finding of Tumwesigye et al. [6] and Daud et al. [7]. This demonstrates that CP could be considered as a good source of cellulose. The influence of using alkaline and bleaching on the CP composition can increase the cellulose content as desired. The CNF obtained from the procedure I consisted of $1.3 \%$ of hemicellulose, $86.4 \%$ of cellulose, and $2.6 \%$ of lignin. Moreover, these values are close to the CNF obtained from procedure II.

Table 1. The chemical composition of cassava peel (CP) and CP nanofibers.

\begin{tabular}{cccc}
\hline Component & Dried CP & Cellulose Nanofibers (CNF) Procedure I & CNF Procedure II \\
\hline Cellulose (\%) & 40.5 & 86.4 & 90.7 \\
Lignin (\%) & 11.7 & 2.6 & 1.7 \\
Hemicellulose (\%) & 21.4 & 1.3 & 0.8 \\
\hline
\end{tabular}

Figure 1 shows the physical appearances of untreated $\mathrm{CP}$, and CNF obtained from procedures I and II in colloidal and powder forms. The homogenous and stable aqueous suspension were obtained from both procedures (as can be seen in Figure 1b,c).

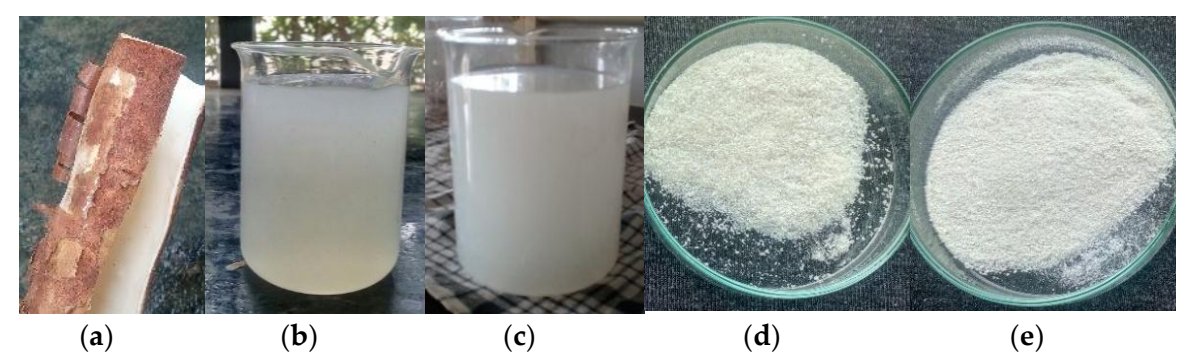

Figure 1. (a) Untreated CP, (b) CNF procedure I colloid, (c) CNF procedure II colloid, (d) CNF procedure I powder, and (e) CNF procedure II powder. 


\subsection{FTIR Analysis}

FTIR was used to determine the absence of lignin and hemicellulose during the cellulose separation process. The data of FTIR from untreated CP, CNF obtained from procedures I and II can be seen in Figure 2. Commercial MCC was used as a data source for pure cellulose spectra. CP is a lignocellulosic material containing main chemical compounds, such as celluloses, hemicellulose, and lignin. The principal contents of the fibers contain several functional groups with different oxygen, such as esters, alkanes, ketones, alcohols, and aromatics [19]. The lignocellulosic materials have characteristic absorbance peaks at $3350 \mathrm{~cm}^{-1}, 2900 \mathrm{~cm}^{-1}, 1740 \mathrm{~cm}^{-1}, 1430 \mathrm{~cm}^{-1}, 1166 \mathrm{~cm}^{-1}$, and $896 \mathrm{~cm}^{-1}$ [20]. The peak appearance around 3500 and $3200 \mathrm{~cm}^{-1}$ indicates the specific $-\mathrm{OH}$ stretching from cellulose [21]. The increase of peak intensity after treatment indicates a rise in the content of cellulose [18]. The peak located at $1734 \mathrm{~cm}^{-1}$ in the spectrum of the raw CPs is referred to the functional group of $\mathrm{C}=\mathrm{O}$ stretching from the groups of acetyl and uronic ester, indicating hemicellulose or ester from carboxylic groups, which refer to p-coumaric and ferulic acid of lignin and/or hemicellulose [22]. This band was decreased a lot in both spectra of CNF and no longer appears in spectra of the MCC due to the high purity of cellulose. The band at $1515 \mathrm{~cm}^{-1}$ that only exists in raw $C P$ was related to $C=C$ lignin aromatic vibration [20]. The absorption peak at $1640 \mathrm{~cm}^{-1}, 1430 \mathrm{~cm}^{-1}$, $1374 \mathrm{~cm}^{-1}$, and $1166 \mathrm{~cm}^{-1}$ was associated with water absorption, $\mathrm{CH}_{2}$ bending vibration, deformation of C-H aromatic ring, and C-O-C linkages, respectively. The peak at $896 \mathrm{~cm}^{-1}$ was assigned to glycoside bond formation of cellulose. Table 2 summarizes the detail FTIR characteristic peak at each sample.

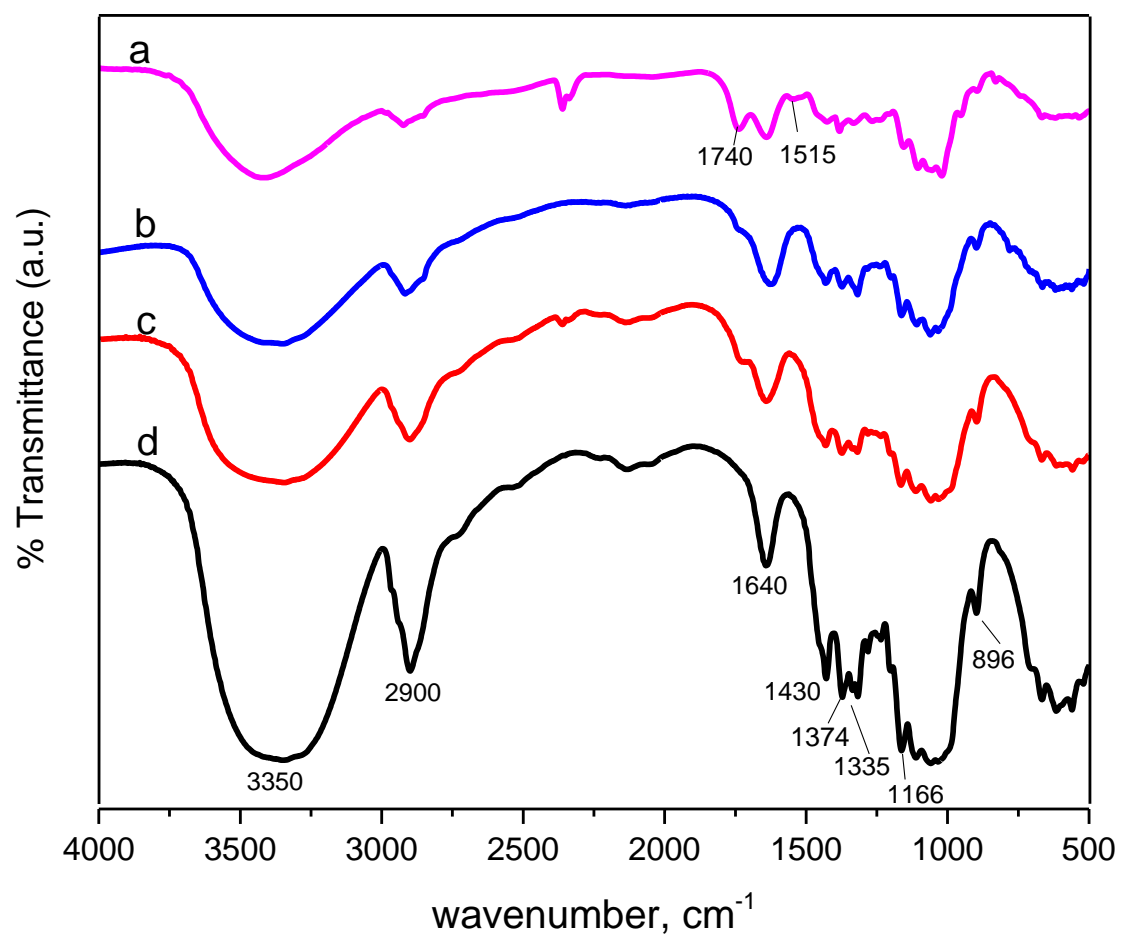

Figure 2. FTIR spectra of (a) raw CPs, (b) CNF procedure I, (c) CNF procedure II, and (d) microcrystalline cellulose (MCC). 
Table 2. Assignment of characteristic absorption peak $\left(\mathrm{cm}^{-1}\right)$ in cellulosic material [18].

\begin{tabular}{ccccl}
\hline Raw CP & CNF Procedure I & CNF Procedure II & MCC & \multicolumn{1}{c}{ Assignment } \\
\hline 3420 & 3345 & 3345 & 3350 & OH stretching \\
2922 & 2920 & 2910 & 2900 & CH stretching of $\mathrm{CH}_{2}$ and $\mathrm{CH}_{3}$ groups \\
$1740 \mathrm{~s}^{*}$ & $1740 \mathrm{w}^{*}$ & $1730 \mathrm{w}$ & - & $\mathrm{C}=$ O stretching of acetyl or carboxylic acid \\
1640 & 1640 & 1640 & 1640 & H-O-H bending of absorbed water \\
1515 & - & - & - & $\mathrm{C}=\mathrm{C}$ stretching of aromatic ring (lignin) \\
1429 & 1430 & 1430 & 1432 & $\mathrm{CH}$ bending \\
1376 & 1374 & 1374 & 1372 & $\mathrm{C}-\mathrm{H}$ deformation \\
1335 & 1335 & 1335 & 1335 & OH in plane bending \\
1166 & 1165 & 1165 & 1164 & $\mathrm{C}-\mathrm{O}-\mathrm{C}$ anti symmetric bridge stretching \\
1062 & 1080 & 1080 & 1080 & $\mathrm{C}=$ O symmetric stretching of primary alcohol \\
- & 896 & 896 & 896 & $\beta-\mathrm{Glycosidic}$ linkages of glucose ring (cellulose) \\
\hline
\end{tabular}

\section{3. $X R D$}

Figure 3 shows the diffractogram of raw CPs, CNF obtained from procedures I and II, and commercial MCC. The diffractogram of both $\mathrm{CNF}$ procedures are similar in appearance. The crystallinity index (CI) points to the comparison of the crystalline toward the amorphous area of cellulose. This was used to determine physical characteristics of the fiber necessary to be used in industry for a special goals, such as thermal stability, elasticity, absorptive capacity, and others. Upgrade of crystallinity is supposed to elevate the rigidity and stiffness, and consequently strength, resulting in a higher resistance toward cracks, therefore allowing the nanocomposites production with the improvement of mechanical properties in nanostructures [23]. The diffraction peak of all samples emerging at $2 \theta$ values of $16^{\circ}$ and $22^{\circ}$ may refer to cellulose I type. The other peak, at about $34.5^{\circ}$, proved that type I of cellulose is stuck in the fiber.

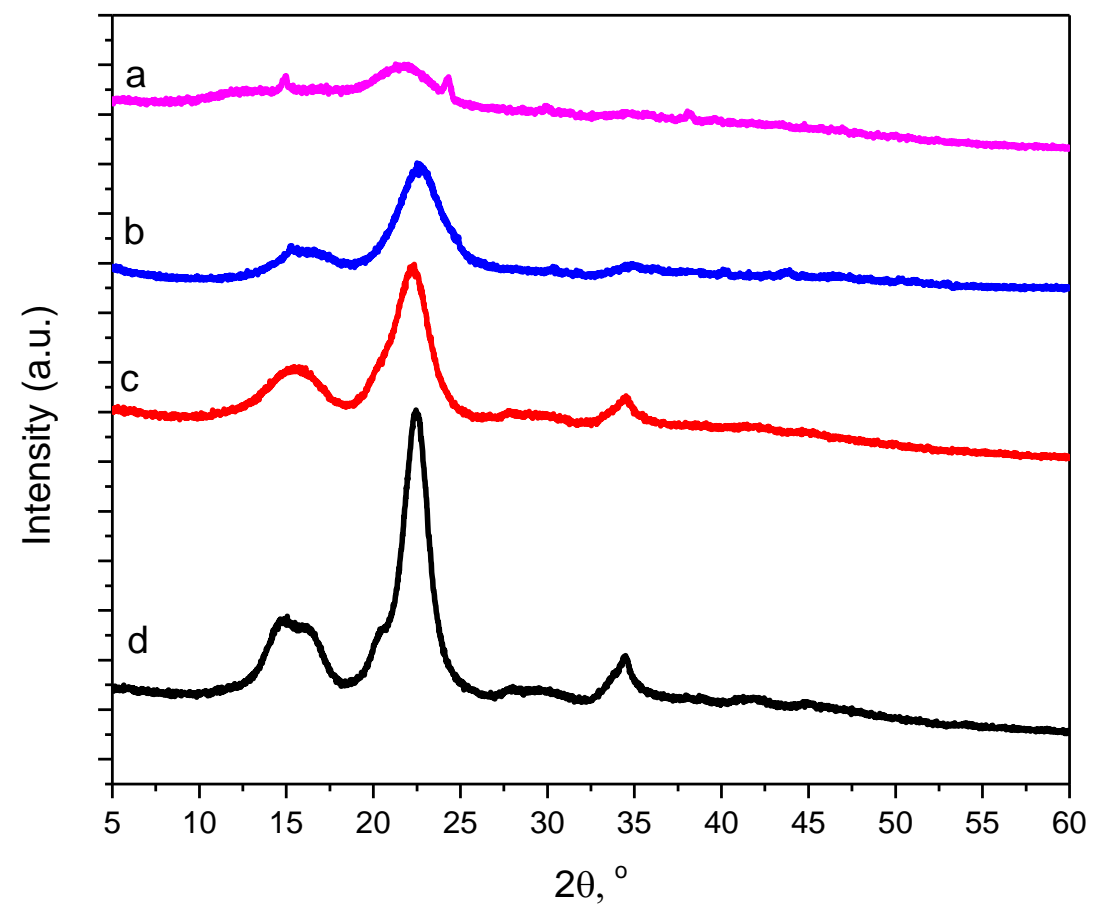

Figure 3. XRD of (a) untreated $\mathrm{CP}$, (b) CNF procedure I, (c) CNF procedure II, and (d) MCC.

Segal method was used to calculate CI with the principal diffraction peak of cellulose I around $22^{\circ}$ and the lowest intensity at around $18^{\circ}$ [24]. It was found that the raw $\mathrm{CP}$ has the lowest $\mathrm{CI}$ of $21.9 \%$, since it contains a great amount of amorphous area. After nanofibers preparation via mechanical (CNF 
procedure I) and acid hydrolysis (CNF procedure II), the crystallinity of the fibers raised to $62.1 \%$ and $63.3 \%$, respectively (Table 3). This occurred because the deletion of hemicelluloses and lignin bound to the fibers of cellulose. As expected, MCC showed the highest CI of $78.3 \%$, due to its high purity of cellulose. The increase of the crystallinity upon acid hydrolysis indicated the dissolution of an amorphous region of the cellulosic fibers. The sulphuric acid attacks and penetrates the amorphous region of the cellulose during the hydrolysis process permitting the hydrolytic disruption of glycosidic bonds and, finally, liberating individual crystallites [19].

Table 3. Crystallinity index (CI) (\%) of raw CP, CNF procedures I and II, and commercial MCC.

\begin{tabular}{lccc}
\hline \multicolumn{1}{c}{ Samples } & $\mathbf{2 \theta}$ Amorphous $\left(^{\circ}\right)$ Intensity & $\left.\mathbf{2 \theta ( 2 0 0 )} \mathbf{(}^{\circ}\right)$ Intensity & CI (\%) \\
\hline Raw CP & 306 & 392 & 21.9 \\
CNF Procedure I & 303 & 799 & 62.1 \\
CNF Procedure II & 325 & 886 & 63.3 \\
MCC & 305 & 1408 & 78.3 \\
\hline
\end{tabular}

\subsection{Thermal Gravimetric Analysis (TGA)}

TGA and differential thermal gravimetric (DTG) curves of the raw CP and CNF obtained from procedures I and II are shown in Figures 4 and 5, respectively. Table 4 summarizes the characteristic of the sample's thermal properties extracted from the curves. Cellulose, hemicellulose, and lignin, as the major component of lignocellulosic materials, are decomposed at different temperatures. Cellulose starts to decompose at $315{ }^{\circ} \mathrm{C}$ and continues up to $400{ }^{\circ} \mathrm{C}$. Hemicellulose begins its decomposition at $220^{\circ} \mathrm{C}$ and persists until $315^{\circ} \mathrm{C}$. Meanwhile, lignin decomposition is extended to a wide temperature range from 200 and $700{ }^{\circ} \mathrm{C}$. The percentage of solid residual after pyrolysis at $700{ }^{\circ} \mathrm{C}$ for cellulose, hemicellulose, and lignin are 6.5, 20, and $46 \mathrm{wt} . \%$, respectively [25]. The TG results (Figure 4) disclosed two major degradation stages: the first is in the range of low temperature under $150{ }^{\circ} \mathrm{C}$ and then in the high temperature with a range from 200 to $600{ }^{\circ} \mathrm{C}$. In the range of $25-150{ }^{\circ} \mathrm{C}$, a little mass disappearance (less than $10 \%$ ) was found for all specimens because of the evaporation of materials humidity. Decomposition of the raw $\mathrm{CP}$ displays a number of steps, demonstrating the existence of different component in the sample that decomposed at different temperature. In the temperature of $200-600{ }^{\circ} \mathrm{C}$, loss of relative mass will be greater (over than $60 \%$ ) as a consequence of main thermal lignocellulosic materials' decomposition. Decomposition of CNF resulting from procedures I and II at $600{ }^{\circ} \mathrm{C}$ are close to $16-20 \mathrm{wt} . \%$.

DTG curves (Figure 5) led the investigation of the maximum mass loss rate of the samples. A small peak appears at $250{ }^{\circ} \mathrm{C}$ during the decomposition of raw $\mathrm{CP}$. This peak was attributed to hemicellulose decomposition [25]. CNF that resulted from procedure I started decomposing at a lower temperature than the one that resulted from procedure II, and it showed a higher amount of residual product. This result supports the data in Table 1, i.e., that the remaining lignin and hemicellulose content in $\mathrm{CNF}$ that resulted from procedure I were higher than the CNF that resulted from the procedure II. 


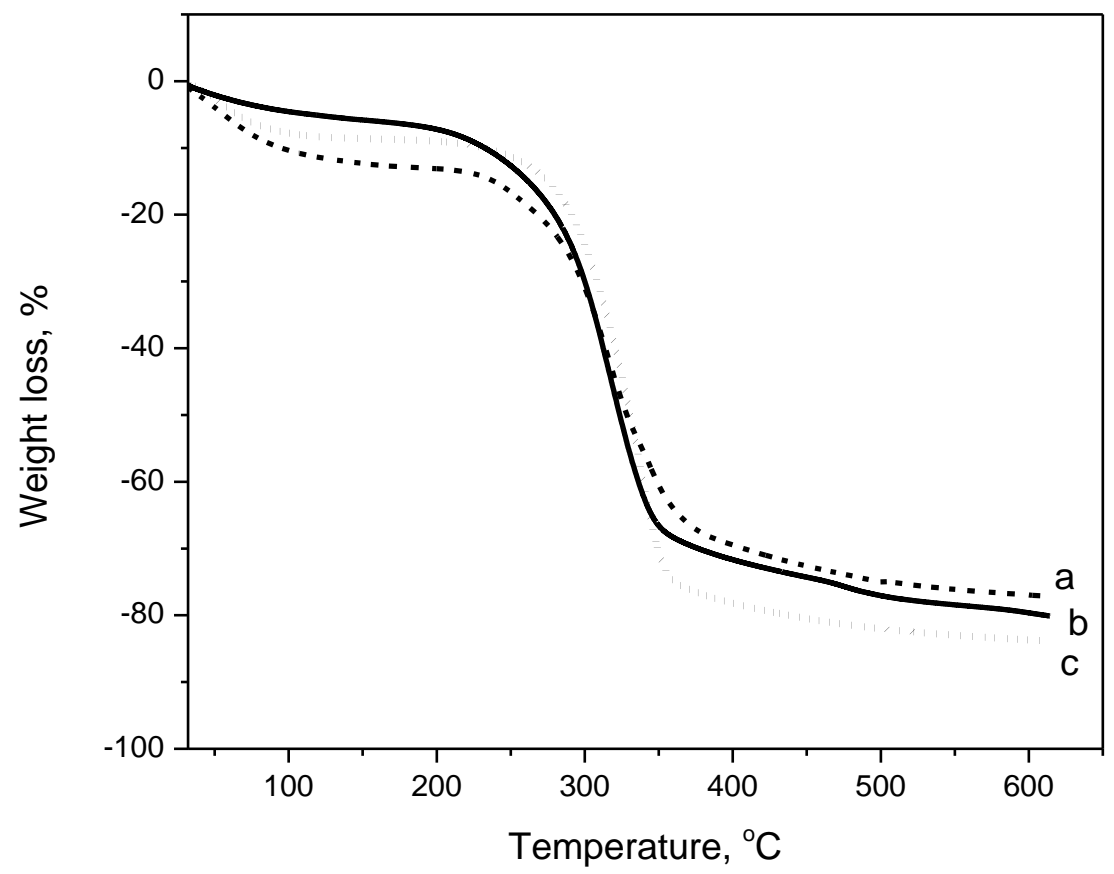

Figure 4. Thermogravimetric (TG) curve of (a) raw CP, (b) CNF procedure I, and (c) CNF procedure II.

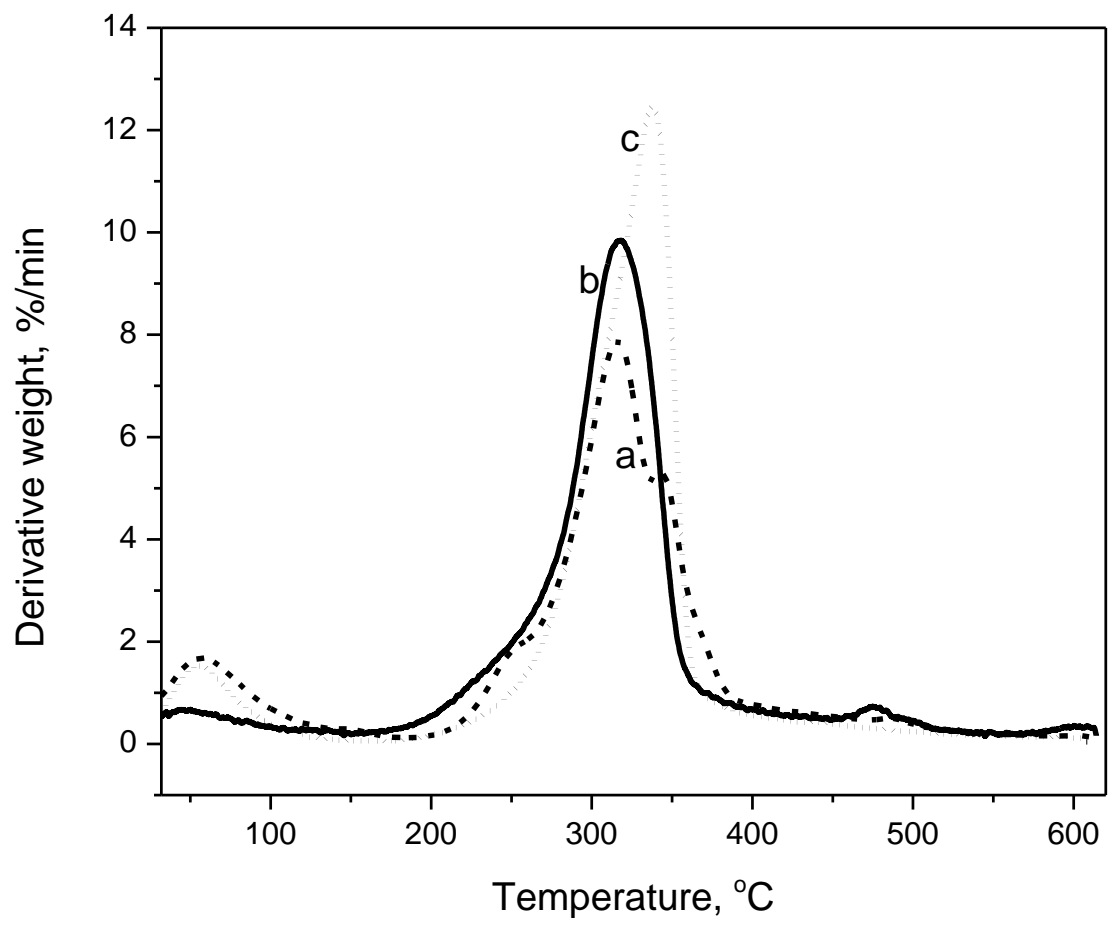

Figure 5. Derivative thermogravimetric (DTG) curve of (a) raw $\mathrm{CP},(\mathbf{b}) \mathrm{CNF}$ procedure I, and (c) CNF procedure II.

Table 4. TG thermal properties of samples.

\begin{tabular}{cccc}
\hline Samples & $\begin{array}{c}\text { Initial Degradation } \\
\text { Temperature }\left({ }^{\circ} \mathbf{C}\right)\end{array}$ & $\begin{array}{c}\text { Maximum Degradation } \\
\text { Rate Temperature }\left({ }^{\circ} \mathbf{C}\right)\end{array}$ & Residue (\%) \\
\hline Raw CP & 215.3 & 315.9 & 22.8 \\
CNF Procedure I & 192.2 & 317.5 & 19.9 \\
CNF Procedure II & 218.7 & 338.2 & 16.2 \\
\hline
\end{tabular}




\subsection{SEM}

SEM images of raw CP and its CNF are displayed in Figure 6. The raw CP has starch constituent more than $60 \%$, and it is clear from the figure that the starch granules from raw CP have been removed after chemical and mechanical treatment at both CNF samples. The presence of a regular arrangement of cellulose fibers in the CNF obtained from procedure I sample can clearly be seen. This corroborates the evidence of a sufficiently high degree of crystallinity in the sample. In the CNF obtained from the procedure II sample, the fiber arrangement was less visible than in the one obtained from the procedure I sample because of the smaller particle size of CNF procedure II that tends to form agglomerate between nanoparticles caused by hydrogen bonds.

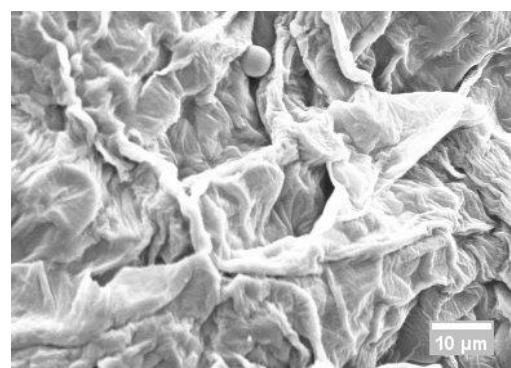

(a)

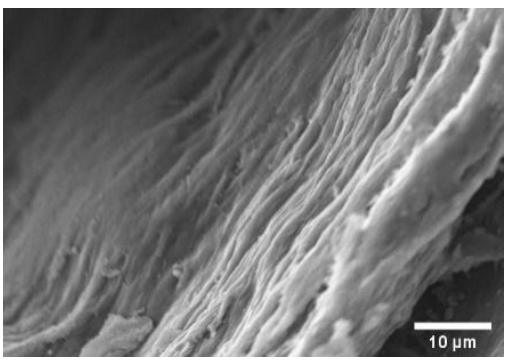

(b)

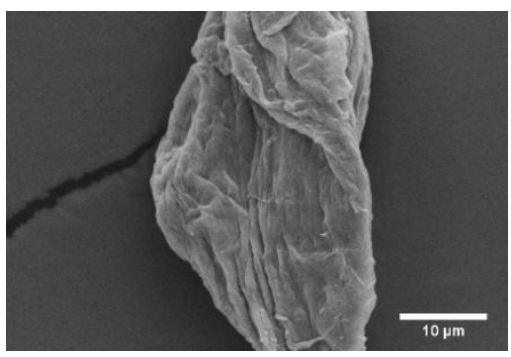

(c)

Figure 6. SEM image of (a) raw $\mathrm{CP},(\mathbf{b}) \mathrm{CNF}$ procedure I, and (c) CNF procedure II.

\subsection{TEM}

Observation of the nanomaterial morphology and nanometer scale was investigated by TEM. The hydrolysis of acid or mechanical disruption was intended to release the amorphous portion of the fiber of cellulose and decrease the fiber size to scale of nanometer. Figure 7 displays the TEM micrographs of both CNF. The figure shows that the appearance of CNF obtained from procedure I is in fiber-form, whereas the one obtained from procedure II is in needle-like configuration with small agglomeration. The CNF procedure II inclines to agglomerate, which had the crystallites stacked together, possibly due to a charge on the ionic surface as an outcome of the acid hydrolysis [23]. The CNF obtained from procedures I and II had an average diameter of 8.2 and $6.7 \mathrm{~nm}$, respectively (Figure 8).

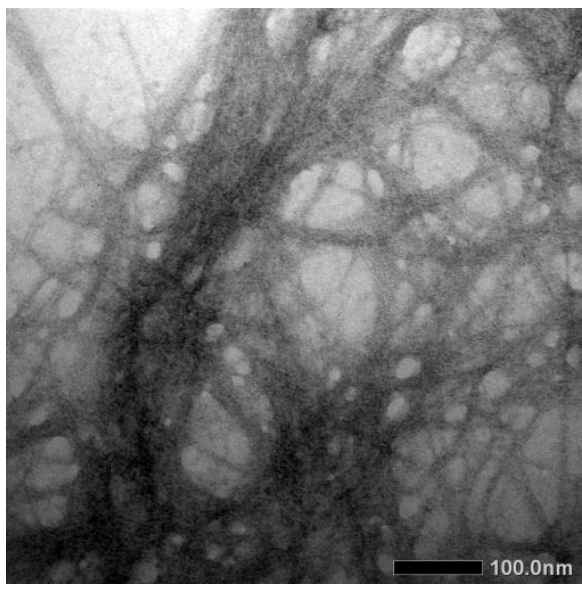

(a)

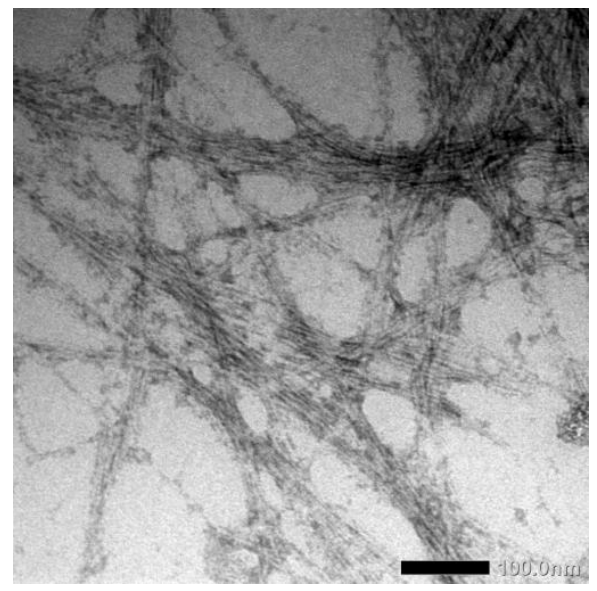

(b)

Figure 7. TEM image of (a) CNF procedure I and (b) CNF procedure II. 


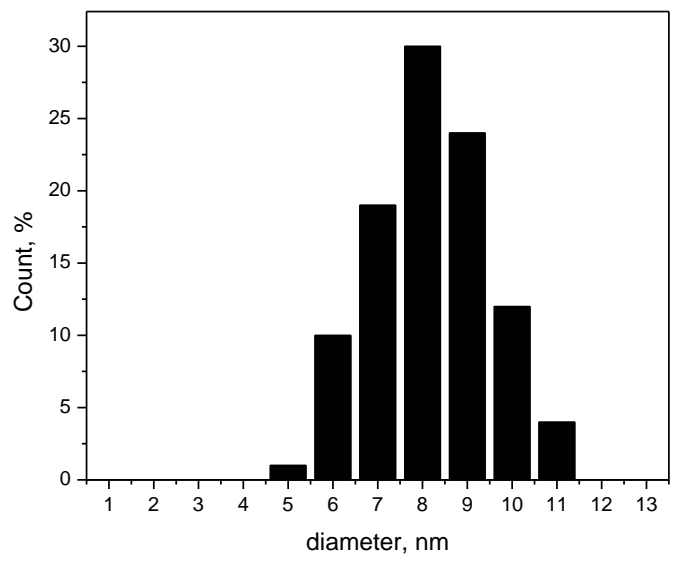

(a)

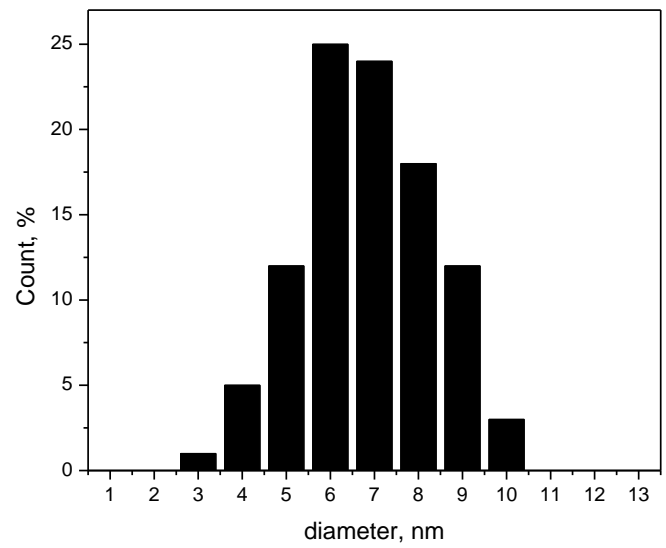

(b)

Figure 8. Diameter distribution of (a) CNF procedure I and (b) CNF procedure II.

\section{Conclusions}

This work was directed to examine the preparation of CNF by avoiding an acid hydrolysis step (Procedure I). The product was then compared with the results of the acid hydrolysis method (Procedure II). Bleaching and alkaline treatments of $\mathrm{CP}$ eliminated great amounts of amorphous substances and provided cellulose as the principal separated portion. Mechanical treatments (homogenization and ultrasonication) effectively produced nanometric cellulose fibers. TEM analysis ensured that CNF were present in the samples which were performed as a treatment. The diffractogram of XRD showed that the crystallinity of CNF from the CPs was higher than the initial dried raw materials. The spectra of FTIR confirmed that the process of bleaching and alkaline effectively released most components of lignin and hemicellulose. The CNF obtained from procedure I had specifications that indicate their feasible utilization as a reinforcement substance in nanocomposite.

Author Contributions: S.W. conducted the experiments, wrote the paper and analyzed the data; I.M.A. as the supervisor of this research provides in-depth analyzed the data; A.R. as the co-promotor provide additional explanation of characterization, E.P. gives his time to help the preparation of samples during experiment. S. provides additional explanation of characterization and improved the paper quality.

Funding: This research received no external funding.

Acknowledgments: The authors thank Indonesian Ministry of Research, Technology and Higher Education (Kemenristekdikti) for BPP-DN scholarship, UPT LTSIT of Lampung University for technical assistance during centrifugation, freeze-drying, TGA, and SEM analysis. We thank Taifo Mahmud from Oregon State University, USA for valuable suggestion through World Class Professor Program-Scheme B 2018.

Conflicts of Interest: The authors declare no conflict of interest.

\section{References}

1. Farias, F.O.; Jasko, A.C.; Colman, T.A.D.; Pinheiro, L.A.; Schnitzler, E.; Barana, A.C.; Demiate, I.M. Characterisation of cassava bagasse and composites prepared by blending with low-density polyethylene. Braz. Arch. Biol. Technol. 2014, 57, 821-830. [CrossRef]

2. FAO. Food Outlook; Biannual Report on Global Food Markets; Food and Agriculture Organization of the United Nation: Rome, Italy, 2018; p. 35. ISBN 978-92-5-130768-7.

3. Teixeira, E.D.M.; Pasquini, D.; Curvelo, A.A.; Corradini, E.; Belgacem, M.N.; Dufresne, A. Cassava bagasse cellulose nanofibrils reinforced thermoplastic cassava starch. Carbohydr. Polym. 2009, 78, 422-431. [CrossRef]

4. Ratnadewi, A.A.I.; Santoso, A.B.; Sulistyaningsih, E.; Handayani, W. Application of cassava peel and waste as raw materials for xylooligosaccharide production using endoxylanase from Bacillus subtilis of soil termite abdomen. Procedia Chem. 2016, 18, 31-38. [CrossRef]

5. Leite, A.L.M.P.; Zanon, C.D.; Menegalli, F.C. Isolation and characterization of cellulose nanofibers from cassava root bagasse and peelings. Carbohydr. Polym. 2017, 157, 962-970. [CrossRef] 
6. Tumwesigye, K.S.; Morales-Oyervides, L.; Oliveira, J.C.; Sousa-Gallagher, M.J. Effective utilisation of cassava bio-wastes through integrated process design: A sustainable approach to indirect waste management. Process Saf. Environ. Prot. 2016, 102, 159-167. [CrossRef]

7. Daud, Z.; Kassim, M.; Sari, A.; MohdAripin, A.; Awang, H.; Hatta, M.; Zainuri, M. Chemical composition and morphological of cocoa pod husks and cassava peels for pulp and paper production. Aust. J. Basic Appl. Sci. 2013, 7, 406-411.

8. Aripin, A.M.; Kassim, A.S.M.; Daud, Z.; Hatta, M.Z.M. Cassava peels for alternative fibre in pulp and paper industry: Chemical properties and morphology characterization. Int. J. Integr. Eng. 2013, 5, 30-33.

9. Wulandari, W.; Rochliadi, A.; Arcana, I. Nanocellulose prepared by acid hydrolysis of isolated cellulose from sugarcane bagasse. IOP Conf. Ser. Mater. Sci. Eng. 2016, 107, 012045. [CrossRef]

10. Kargarzadeh, H.; Ioelovich, M.; Ahmad, I.; Thomas, S.; Dufresne, A. Methods for extraction of nanocellulose from various sources. In Handbook of Nanocellulose and Cellulose Nanocomposites; John Wiley \& Sons/Wiley: Hoboken, NJ, USA, 2017; pp. 1-49. ISBN 3-527-68998-2.

11. Asrofi, M.; Abral, H.; Kasim, A.; Pratoto, A.; Mahardika, M.; Hafizulhaq, F. Mechanical properties of a water hyacinth nanofiber cellulose reinforced thermoplastic starch bionanocomposite: Effect of ultrasonic vibration during processing. Fibers 2018, 6, 40. [CrossRef]

12. Pasquini, D.; de Morais Teixeira, E.; da Silva Curvelo, A.A.; Belgacem, M.N.; Dufresne, A. Extraction of cellulose whiskers from cassava bagasse and their applications as reinforcing agent in natural rubber. Ind. Crops Prod. 2010, 32, 486-490. [CrossRef]

13. de Morais Teixeira, E.; Curvelo, A.A.; Corrêa, A.C.; Marconcini, J.M.; Glenn, G.M.; Mattoso, L.H. Properties of thermoplastic starch from cassava bagasse and cassava starch and their blends with poly (lactic acid). Ind. Crops Prod. 2012, 37, 61-68. [CrossRef]

14. Wicaksono, R.; Syamsu, K.; Yuliasih, I.; Nasir, M.; Street, K. Cellulose nanofibers from cassava bagasse: Characterization and application on tapioca-film. Chem. Mater. Res. 2013, 3, 79-87.

15. Travalini, A.P.; Prestes, E.; Pinheiro, L.A.; Demiate, I.M. Extraction and characterization of nanocrystalline cellulose from cassava bagasse. J. Polym. Environ. 2018, 26, 789-797. [CrossRef]

16. Widiarto, S.; Yuwono, S.; Rochliadi, A.; Arcana, I. Preparation and characterization of cellulose and nanocellulose from agro-industrial waste-cassava peel. IOP Conf. Ser. Mater. Sci. Eng. 2017, 176, 012052. [CrossRef]

17. TAPPI. Alpha-beta- and Gamma-Cellulose in Pulp; T $203 \mathrm{~cm}-99$. The Technical Association of Pulp and Paper Industry. 1999. Available online: https://imisrise.tappi.org/TAPPI/Products/01/T/0104T203.aspx (accessed on 8 October 2018).

18. Viera, R.G.; Rodrigues Filho, G.; de Assunção, R.M.; Meireles, C.D.S.; Vieira, J.G.; de Oliveira, G.S. Synthesis and characterization of methylcellulose from sugar cane bagasse cellulose. Carbohydr. Polym. 2007, 67, 182-189. [CrossRef]

19. Chieng, B.W.; Lee, S.H.; Ibrahim, N.A.; Then, Y.Y.; Loo, Y.Y. Isolation and characterization of cellulose nanocrystals from oil palm mesocarp fiber. Polymers 2017, 9, 355. [CrossRef] [PubMed]

20. Aprilia, N.A.S.; Asniza, M.; Owolabi, F.A.T.; Rizal, S.; Syakir, M.I.; Paridah, M.T.; Kumar, U.S.U.; Nasrullah, R.C.L.; Haafiz, M.K.; Khalil, H.P.S.A. Role of dispersion time on the properties of enzymatic-treated bamboo cellulose nanofibers. Mater. Res. Express 2018, 5, 105014. [CrossRef]

21. Mandal, A.; Chakrabarty, D. Isolation of nanocellulose from waste sugarcane bagasse (SCB) and its characterization. Carbohydr. Polym. 2011, 86, 1291-1299. [CrossRef]

22. Alemdar, A.; Sain, M. Isolation and characterization of nanofibers from agricultural residues-Wheat straw and soy hulls. Bioresour. Technol. 2008, 99, 1664-1671. [CrossRef]

23. Liu, H.; Liu, D.; Yao, F.; Wu, Q. Fabrication and properties of transparent polymethylmethacrylate/cellulose nanocrystals composites. Bioresour. Technol. 2010, 101, 5685-5692. [CrossRef]

24. Segal, L.; Creely, J.J.; Martin, A.E., Jr.; Conrad, C.M. An empirical method for estimating the degree of crystallinity of native cellulose using the X-ray diffractometer. Text. Res. J. 1959, 29, 786-794. [CrossRef]

25. Morán, J.I.; Alvarez, V.A.; Cyras, V.P.; Vázquez, A. Extraction of cellulose and preparation of nanocellulose from sisal fibers. Cellulose 2008, 15, 149-159. [CrossRef]

(C) 2019 by the authors. Licensee MDPI, Basel, Switzerland. This article is an open access article distributed under the terms and conditions of the Creative Commons Attribution (CC BY) license (http://creativecommons.org/licenses/by/4.0/). 